\title{
EFFECT OF PLATELET RICH FIBRIN ON BONE HEALING IN SMALL PERIAPICAL LESIONS WITH SIMULTANEOUS IMMEDIATE IMPLANTATION IN MAXILLARY AESTHETIC ZONE
}

\author{
Nesrine Khairy *, Abeer Kamal ${ }^{* *}$ and Basma Mousa ${ }^{* * *}$
}

\begin{abstract}
Aim: To evaluate the efficiency of using platelet rich fibrin (PRF) in small chronic periapical lesions with simultaneous immediate implant placement in maxillary anterior esthetic region.

Patients and Methods: Seven cases with small size periapical lesions in the upper anterior aesthetic zone need immediate implantation were selected. After flapless tooth extraction and curettage of the lesion, platelet-rich fibrin (PRF) was applied in the bony defect and TIXOS implant was inserted simultaneously. CBCT was used immediately and 6 months post implantation to evaluate the mean of bone density in the defect area.
\end{abstract}

Results: There was increase in the mean of bone density after six months post implantation and it was statistical significant.

Conclusions: Platelet-rich fibrin in patients with chronic periapical lesions allow proper bone healing with immediate implant placement in maxillary anterior aesthetic zone.

KEYWORDS: Platelet rich fibrin, immediate implantation, TIXOS implant.

\section{INTRODUCTION}

Immediate dental implants are considered treatment option to restore function, esthetics, preserve coronal bone from resorption after extraction and allow new bone apposition around the neck of the implants. ${ }^{(1)}$ Many authors stated that it is contraindicated to use immediate dental implant in area with periapical and/or periodontal lesions since the healing process will be impaired due to the presence of microbial interference..$^{(2-3)}$ Recently several reports studied the immediate implants after the extraction in the presence of chronic periapical infection with high rate of success up-to $98.4 \% .{ }^{(4-8)}$

A retrospective study was conducted by Fugazzotto $^{(9)}$ with dental implants placed in periapically infected and healthy sites and compared

\footnotetext{
* Lecturer of Oral \& Maxillofacial Surgery, Faculty of Dentistry, Cairo University, Cairo, Egypt.

** Associate Professor of Oral \& Maxillofacial Surgery, College of Oral and Dental Surgery, Misr University for Science and Technology, Egypt.

*** Professor of Oral \& Maxillofacial Surgery, Faculty of Dentistry, Cairo University, Cairo, Egypt.
} 
the success rate on both groups. The study was concluded that the success of osseointegration, stability and absence of periimplantitis were $97.5 \%$ for the periapical infection group and $98.7 \%$ for the healthy group. Therefore, placement of immediate dental implants in periapically infected area is a harmless and a feasible treatment protocol with high success rate and rapidly improving the aesthetics and function.

Platelet rich fibrin (PRF) was initially established by Choukroun et al. ${ }^{(10)}$ It is considered the secondgeneration of platelets concentrate. It eliminated the risks associated with the use of platelet rich plasma (PRP) with bovine thrombin for its activation. ${ }^{(10-11)}$ It is a leukocyte and platelet rich fibrin biomaterial, and It releases significantly large quantities of coagulation and healing molecules after application till more than seven days. This released factors include growth factors as transforming growth factor- $\beta 1$ (TGF- $\beta 1$ ), platelet-derived growth factors (PDGF) and vascular endothelial growth factor(VEGF) and glycoproteins as thrombospondin-1, and fibronectin which activate fibroblasts and osteoblasts promoting protein synthesis and wound healing of both soft and hard tissues. Platelet rich fibrin has been proven adequate regeneration of bone in different reconstruction procedures. ${ }^{(12-17)}$

The aim of present study was to evaluate the efficiency of using PRF in small chronic periapical lesion with simultaneous immediate implantation of Tixos implant in maxillary anterior esthetic region. It was hoped that the finding of the present study allows immediate implant placement in areas with small chronic infections to maintain alveolar bone height, healthy gingival tissue, and enhance aesthetics and function.

\section{PATIENTS AND METHODS}

Seven cases need immediate implantation for upper anterior aesthetic zone were selected from the Outpatient Clinic of Oral and Maxillofacial Surgery Department, Faculty of Dentistry, Cairo University.
The age of patients ranged from 22 to 47 years with a mean of 34.5 years. Inclusion criteria: Patients with badly broken tooth due to trauma, excessive internal tooth resorption, endodontic failure, extensive dental caries or advanced periodontitis with small size periapical lesion (not more than 5 $\mathrm{mm}$ in diameter). ${ }^{(18)}$

Exclusion criteria: pregnant female, history of bone disease, uncontrolled diabetes, irradiated bone, heavy smoking habit or immunosuppressive therapy, acute periapical pathology, and any mandibular parafunctional habits. Agreement for this study was obtained from the ethical committee and informed written consent was achieved from all patients to be included in this study.

Clinical examination, and diagnostic casts for inter-arch relation and evaluation of the status of the alveolar ridge at the site of implant placement were performed. Digital panoramic radiograph was performed to evaluate the condition of the remaining tooth and/or root, size of the radiolucent area and adequacy of the remaining bone surrounded the infected tooth. Figure (1). Cone beam computed tomogram (CBCT) was taken to evaluate the bone quality, quantity, determine implant diameter, length, site and the relation of important structures as nasal cavity.

\section{Surgical technique:}

The patients were given $300 \mathrm{mg}$ of clindamycin (Dalacin-C Capsule, Memphis Chemical Co, CairoEgypt) orally one hour preoperative and $0.2 \%$ chlorhexidine gluconate mouth wash (Hexitol, the Arab Drug Co, Cairo-Egypt). The patients were draped and surgical kit were prepared. Surgical procedures were performed under local anesthesia using 2\% Mepicaine-L (Mepivicaine-HCL 2\% with Levonordefrin 1: 20,000, Alex, Co. Egypt). A flapless atraumatic extraction of the teeth was performed to ensure intact buccal bone using the periotome. Figure (2). Using straight surgical curette for complete removal of the periapical lesion, followed by sequential preparation of the osteotomy 
site. To obtain the primary stability of the implant the palatal wall was engaged and drilling 2-3 mm extension beyond the apex of the extraction socket.

\section{Production of PRF:}

Ten $\mathrm{ml}$ of patients' blood was drawn into $10 \mathrm{ml}$ test tubes without an anticoagulant and centrifuged immediately using a table top centrifuge at 2,700 rpm for 12 minutes $^{(7)}$, the resultant product consists of: top most layer of poor platelet plasma (PPP), PRF the middle and red blood cells (RBCs) at the bottom which was removed and apply the PRF in the surgical defect apically before implant insertion.

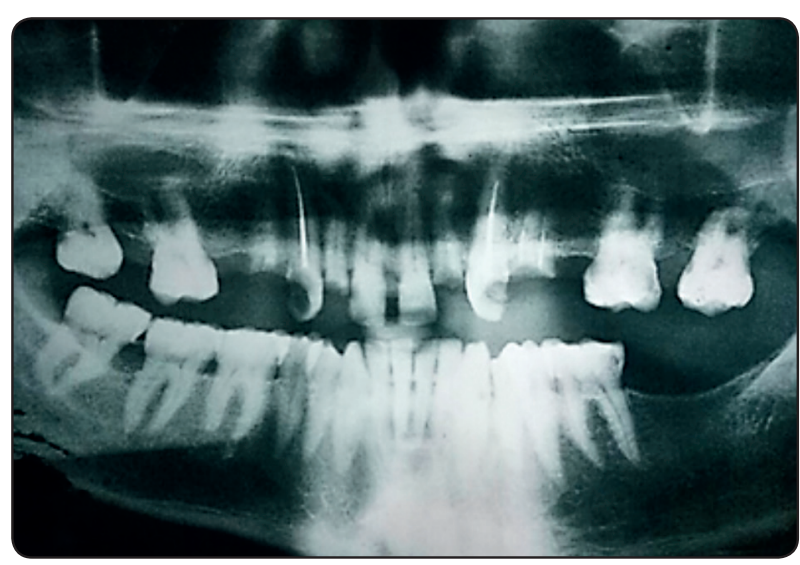

Fig. (1) Preoperative digital panoramic radiograph 1:1 showing the teeth to be implanted with small periapical lesions

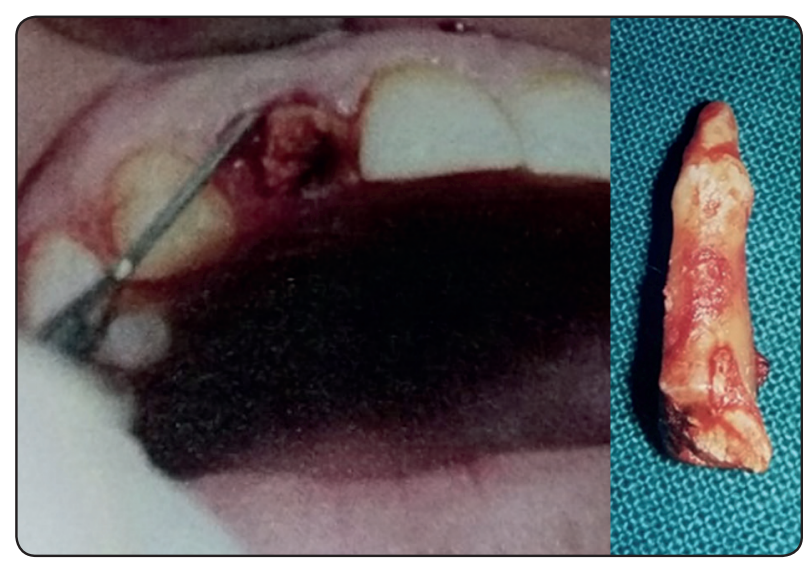

Fig. (2) A photograph showing atraumatic surgical extraction

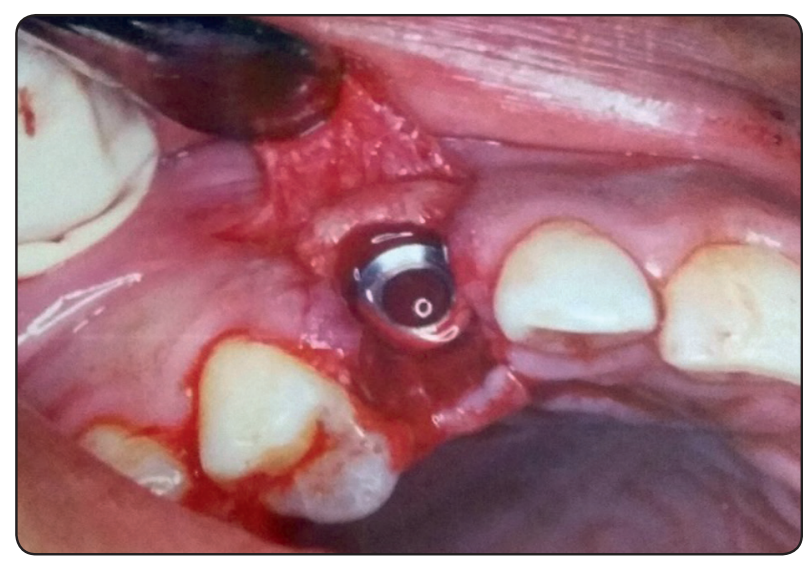

Fig. (3) a photograph showing subcrestal implant insertion USA. 2016). This was followed by Tukey's post hoc test when the test revealed a significant difference. The significance level was set at $\mathrm{P}<0.05$. 


\section{RESULTS}

The post-operative course was uneventful. Slight swelling was noticed at the first week. Primary wound healing was observed in all patients. No signs of infection, flap dehiscence or threads exposure were seen in all cases. The histologic examination of the specimens revealed mass of granulation tissue represent the periapical granulomas.

\section{Result of measurement of bone density by CBCT}

The mean score increased from $-716.43 \pm 126.2$ immediate postoperative, to $-107 \pm 111.6$ after 6 months postoperative. Paired t test revealed that the difference was statistically significant with $\mathrm{p}$ value 0.000002 . Tukey's post hoc test revealed significant difference between values recorded at immediate post-operative and 6 months post-operative. Table (1), figures $(4,5,6,7)$.

TABLE (1): Mean bone density (HU) and significance of the difference using one-way analysis of variance (ANOVA) test

\begin{tabular}{|l|c|c|c|c|c|c|c|}
\hline Bone density & Min. & Max. & Mean & Std. Error & Std. Deviation & T & P value \\
\hline Immediate postop. & -902 & -526 & -716.5 & 0.981 & 126.2 & -2.57 & $0.000002 *$ \\
\hline 6months postop. & -215 & 46 & -107 & 0.841 & 111.6 & & \\
\hline
\end{tabular}

Significance level $p<0.05$, * significant

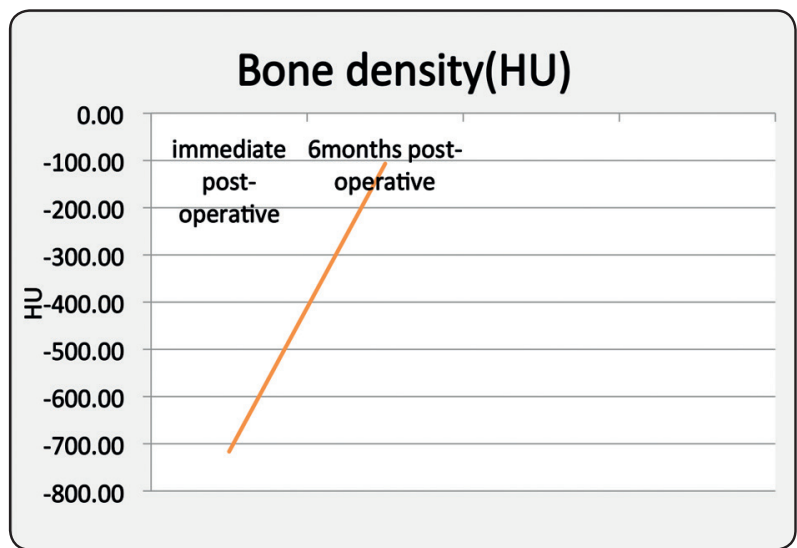

Fig. (4) Graph showing increase in mean bone density 6 months postoperatively

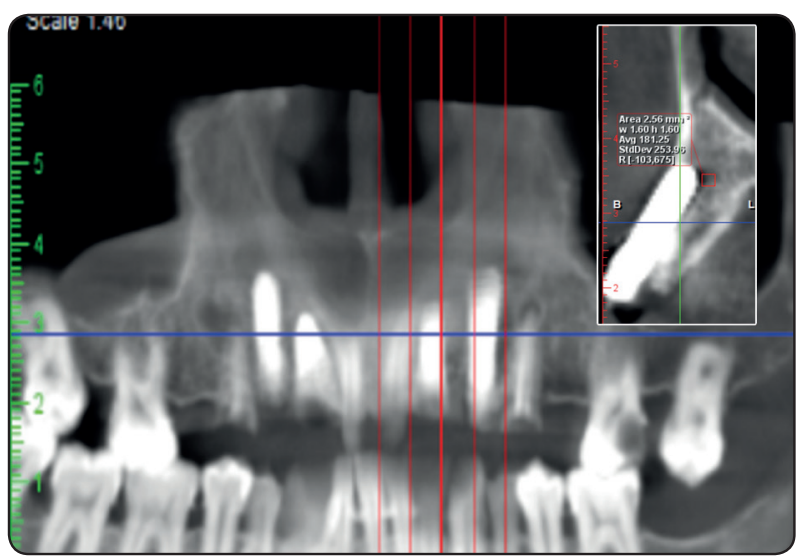

Fig. (6) 6 months postoperative CBCT determining mean bone density

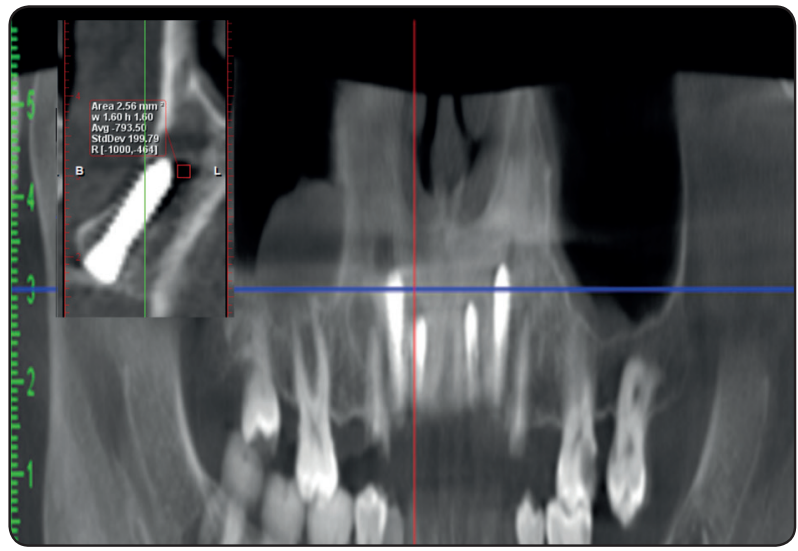

Fig. (5) Immediate postoperative CBCT determining mean bone density

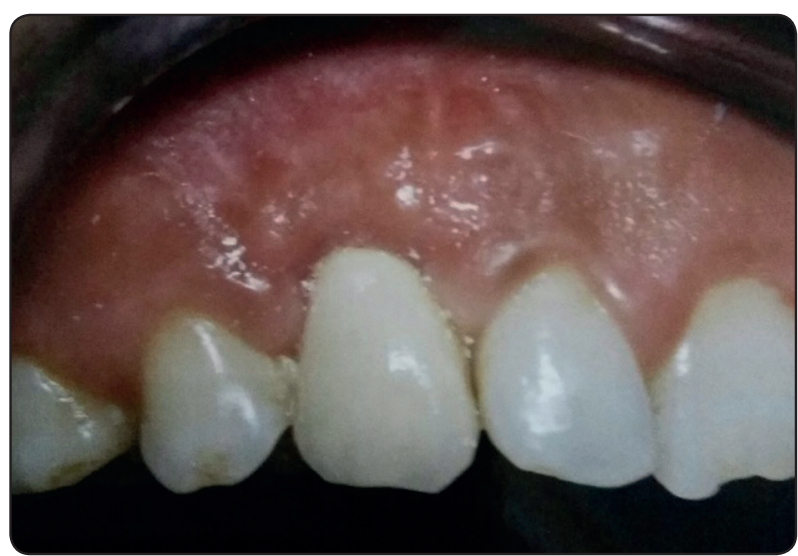

Fig. (7) a photograph showing the final restoration 6 months post-implantation 


\section{DISCUSSION}

The concept of immediate implantation and even immediate loading for anterior teeth is important for the patients to preserve aesthetics and functions after teeth extraction. Immediate implant placement in fresh extraction socket has been proposed to preserve alveolar bone dimensions, gingival margin position, gingival thickness and keratinized gingival tissue. Placement of implant in infected areas is still controversial with little scientific or clinical consensus about the success rate. This study was conducted to evaluate the effect of PRF on bone healing in area having small periapical bone defect with simultaneous immediate implantation following tooth extraction in the maxillary aesthetic zone.

In this study, the teeth were extracted atraumatically using a periotome in order to leave the buccal bone intact. Flapless approach was used in this study to minimize the dimensional changes in the ridge; this is in agreement with Mazzocco et al (16) and Tarnow et al ${ }^{(19)}$ who indicated that only $1 \mathrm{~mm}$ or less of change was shown for all implant treatment groups that were performed as flapless placement. Flapless technique also prevent separation of periosteum and blood supply out of the area to permit better healing without soft tissue recession in the anterior zone. Alert debridement, with pre and postoperative antibiotics allowed a favorable basis for bone healing, increase bone density with subsequent osseointegration of implant. This technique agrees with many authors. ${ }^{(20-23)}$

All the seven cases showed regular primary wound healing and throughout the follow up period there were no clinical signs of infection, wound dehiscence or implant exposure with proper primary and final implant stability. The tissues around the crowns was enhanced by strict oral hygiene that was maintained in all patients.

Tixos implant was used in the current study, with a new technology applied to titanium using laser which; allows the production of a porous surface characterized by open intercommunicating cavities that proved the capability of this surface to accelerate healing of bone. The mechanical features of Tixos implant and, the surface morphology promote bone healing, enhancing three-dimensional (3D) organization of fibrin network, cell migration, adhesion, and nutritional elements exchanges with the progress of proper vascularization targeting to the organization of bone matrix.

In the present study PRF was used as autologous healing biomaterial and free from any additives (no anticoagulant and no chemicals for activation). It can be prepared simply, without time consuming (about 15 minutes). The use of these PRF for its importance in stimulation of bone and gingival healing during augmentations and rehabilitations using dental implants. Its effect on soft tissue healing and maturation is particularly significant. Uses of PRF is in agreement with many authors $(7,9,24)$

In the present study there was significant increase in mean bone density at the area with periapical lesion surrounded the dental implant after six months postoperatively. This attributed to the healing properties and growth factors presented in PRF that being released up to 7 days. The PRF is a healing biomaterial with a great potential for bone and soft tissue regeneration, without inflammatory reactions. It promotes hemostasis, bone growth and maturation as well as a supportive matrix. The slower release of growth factors from PRF allow cells to migrate and promote healing of bony cells with increase in bone mineralization gradually to reach $60 \%$ at the 6 months post-implantation. This concept is in agreement with many authors. ${ }^{(25-29)}$

The present study concluded that platelet-rich fibrin indicated for appropriate bone healing and soft tissue regeneration if it placed in patients with small chronic periapical lesions associated with immediate implant placement in maxillary anterior aesthetic zone, Platelet rich fibrin enhanced bone regeneration and is time saving for the patient comfort. This study recommended immediate implant placement into sockets with small surgically removed periapical pathology, when appropriate debridement and cleaning, with the use of systemic antibiotics are used. 


\section{REFERENCES}

1. Crespi R, Capparè P, Gherlone E. Fresh-Socket Implants in Periapical Infected Sites in Humans. J Periodontol. 2010;81(3):378

2. Quirynen M, Gijbels F, Jacobs R. An infected jaw bone site compromising successful osseointegration. Periodontol 2000. 2003; 33:129-144.

3. Rosenquist B, Grenthe B. Immediate placement of implants into extraction sockets: Implant survival. Int J Oral Maxillofac Implants 1996; 11:205-209

4. Siegenthaler DW, Jung RE, Holderegger C, Roos M, Hammerle CH. Replacement of teeth exhibiting periapical pathology by immediate implants: A prospective, controlled clinical trial. Clin Oral Implants Res 2007; 18:727-737.

5. Lindeboom JA, Tjiook Y, Kroon FH. Immediate placement of implants in periapical infected sites: A prospective randomized study in 50 patients. Oral Surg Oral Med Oral Pathol Oral Radiol Endod 2006;101: 705-710.

6. Novaes AB Jr., Vidigal Ju'nior GM, Novaes AB, Grisi MF, Polloni S, Rosa A. Immediate implants placed into infected sites: A histomorphometric study in dogs. Int J Oral Maxillofac Implants 1998; 13:422-427

7. Del Fabbro M, Boggian C, Taschieri S. Immediate implant placement into fresh extraction sites with chronic periapical pathologic features combined with plasma rich in growth factors: Preliminary results of single-cohort study. J Oral Maxillofac Surg. 2009 ;67(11):2476-84.

8. Bell CL, Diehl D, Bell BM, Bell RE. The Immediate Placement of Dental Implants into Extraction Sites With Periapical Lesions: A Retrospective Chart Review. J Oral Maxillofac Surg. 2011;69(6):1623-7.

9. Fugazzotto PA: A retrospective analysis of implants immediately placed in sites with and without periapical pathology in sixty-four patients. J Periodontol. 2012; 83:182-6.

10. Choukroun J, Adda F, Schoeffler C, Vervelle A. Une opportunité en paro-implantologie: Le PRF. Implantodontie. $2000 ; 42: 55-62$.

11. Carlson ER. Bone grafting the jaws in the 21 st century: The use of platelet-rich plasma and bone morphogenetic protein. Alpha Omegan 2000; 93(3):26-30.

12. Garg AK. The use of platelet-rich plasma to enhance the success of bone grafts around dental implants.Dent Implantol Update. 2000;11(3):17-21.
13. Sunitha Raja V, Munirathnam Naidu E. Platelet-rich fibrin: evolution of a second-generation platelet concentrates. Indian J Dent Res. 2008 Jan-Mar;19(1):42-6.

14. Mazor Z, Horowitz RA, Del Corso M, Prasad HS, Rohrer MD, Dohan Ehrenfest DM. Sinus floor augmentation with simultaneous implant placement using Choukroun's platelet-rich fibrin as the sole grafting material: A radiologic and histologic study at 6 months. J Periodontol. 2009;80(12):2056-64.

15. Pantaleo G, Amato M, Howard CM, Pedicini L, Claudio PP. Platelet Rich Fibrin (PRF)in Implants Dentistry in Combination with New Bone Regenerative Flapless Technique: Evolution of the Technique and Final Results. Open Med (Wars). 2017 Mar 9;12:24-32.

16. Mazzocco F, Jimenez D, Barallat L, Paniz G, Del Fabbro M, Nart J. Bone volume changes after immediate implant placement with or without flap elevation. Clin Oral Implants Res. 2017;28(4):495-501.

17. Li Q, Pan S, Dangaria SJ, Gopinathan G, Kolokythas A, Chu S, Geng Y, Zhou Y, Luan X. platelet rich fibrin promotes periodontal regeneration and enhances alveolar bone augmentation. Biomed Res Int. 2013; 26.

18. Vajgel A, Mardas N, Farias BC, Petrie A, Cimões R, Donos N. A systematic review on the critical size defect model. Clin Oral Implants Res. 2014;25(8):879-93.

19. Tarnow DP, Chu SJ, Salama MA, Stappert CF, Salama H, Garber DA, Sarnachiaro GO, Sarnachiaro E, Gotta SL, Saito H. Flapless post extraction socket implant placement in the esthetic zone: part 1 . The effect of bone grafting and/or provisional restoration on facial-palatal ridge dimensional change-a retrospective cohort study. Int J Periodontics Restorative Dent. 2014;34(3):323-31.

20. Novaes AB Jr, Vidigal GM Jr, Novaes AB, Grisi MFM, Polloni S, Rosa A. Immediate implants placed into infected sites: A histomorphometric study in dogs. Int J Oral Maxillofac Implants. 1998; 13(3):422-7.

21. Novaes AB Jr, Novaes AB. Immediate implants placed into infected sites: a clinical report. Int J Oral Maxillofac Implants. 1995; 10(5):609-13.

22. Lindeboom JA, Tjiook Y, Kroon FH. Immediate placement of implants in periapical infected sites: a prospective randomized study in 50 patients. Oral Surg Oral Med Oral Pathol Oral Radiol Endod. 2006;101(6):705-10.

23. Siegenthaler DW , Jung RE, Holderegger C, Roos M, Hämmerle CH F. Replacement of teeth exhibiting periapical pa- 
thology by immediate implants. A prospective controlled clinical trial. Clin Oral Impl Res. 2007; 18(6):727-37.

24. Dohan Ehrenfest DM, Bielecki T, Del Corso M, Inchingolo F, Sammartino G. Shedding light in the controversial terminology for platelet-rich products: platelet-rich plasma (PRP), platelet-rich fibrin (PRF), platelet-leukocyte gel (PLG), preparation rich in growth factors (PRGF), classification and commercialism. J Biomed Mater Res A. 2010; 95(4):1280-2.

25. Gassling V, Purcz N, Braesen JH, Will M, Gierloff M, Behrens E, Açil Y, Wiltfang J. Comparison of two different absorbable membranes for the coverage of lateral osteotomy sites in maxillary sinus augmentation: A preliminary study. J Craniomaxillofac Surg. 2013;41(1):76-82.

26. Pradeep AR, Rao NS, Agarwal E, Bajaj P, Kumari M, Naik
SB. Comparative evaluation of autologous platelet-rich fibrin and platelet-rich plasma in the treatment of 3-wall intrabony defects in chronic periodontitis: A randomized controlled clinical trial. J Periodontol. 2012; 83(12):1499-507.

27. Kumar RV, Shubhashini N. Platelet rich fibrin: A new paradigm in periodontal regeneration. Cell Tissue Bank. Cell Tissue Bank. 2013;14(3):453-63.

28. Ozdemir H, Ezirganli S, Isa Kara M, Mihmanli A, Baris E. Effects of platelet rich fibrin alone used with rigid titanium barrier. Arch Oral Biol. 2013;58(5):537-44.

29. Dohan DM, Choukroun J, Diss A, Dohan SL, Dohan AJ, Mouhyi J, Gogly B. Platelet-rich fibrin (PRF): A second-generation platelet concentrate. Part II: Platelet-related biologic features Oral Surg Oral Med Oral Pathol Oral Radiol Endod. 2006;101(3):e45-50. 